\title{
COMBINING AGILE APPROACHES AND RISK MANAGEMENT FOR MECHATRONIC PRODUCT DEVELOPMENT - A CASE STUDY
}

\author{
J. Trauer ${ }^{凶}$, S. Schweigert-Recksiek, K. Gövert, M. Mörtl and U. Lindemann \\ Technical University of Munich, Germany \\ $\triangle$ jakob.trauer@tum.de
}

\begin{abstract}
As the benefits and potentials of agile approaches become increasingly clearer, also hardware product development seeks to apply those methods and procedures. However, mechatronic hardware products are often subject to stricter safety regulations so that a consequent risk management is essential. This paper presents a risk management method suitable for agile product development projects. The method together with an adapted agile procedure were applied and evaluated in a successful industrial case study. This lead to the extended application of agile approaches in other parts of the company.
\end{abstract}

Keywords: agile development, product development, risk management, small and medium size enterprise (SME)

\section{Introduction}

Agile means being flexible, adaptable, and fast regarding environmental and project changes (Hofert, 2016). The approach is based on the agile manifesto, which is written for the software development (Beck et al., 2001). In the last few years more and more companies started to implement the agile approach into the mechatronic product development to use the advantages of agility (Schmidt et al., 2018; Albers et al., 2018). But the agile approach cannot be transferred to the mechatronic product development without adaptions to different boundary conditions (Klein, 2016; Goevert et al., 2019). Team members of a mechatronic development project deal with suppliers and the production for example. This results in more external dependencies and external uncertainties (Goevert, 2020). The short sprints and development cycles of prototypes support the philosophy to "fail fast and learn fast", which reduce long-term project risks (Boehmer, 2018). However, uncertainties and risks of each sprint cannot be eliminated. One opportunity to reduce the project risk of mechatronic product development projects is risk management but it is typically a detailed non-agile process (Project Management Institute, 2017).

Consequently, the goal of this paper is to adapt the agile approach to a mechatronic development project and combine the agile approach with elements of risk management in a case study. The results presented are based on a case study conducted together with "SEBA Hydrometrie GmbH \& Co. KG", a Bavarian small and medium sized enterprise (SME) producing hydrological devices. In the following, the state of the art is going to be presented in section 2. Section 3 entails the research question and methodology. The agile project and the developed risk assessment tool are presented in sections 4 and 5, before the approach is evaluated in section 6 . The paper is concluded in section 7 . 


\section{State of the art}

The state of the art focuses on general agile frameworks and on frameworks of agile mechatronic product development as well as on approaches integrating risk management to an agile development. The most common agile development approach is Scrum. Scrum is a general agile framework, which combines an agile process, roles, and artefacts. It is an iterative process that includes sprint plannings, sprints, retrospectives, and reviews. After each sprint, the development team present a prototype to the product owner and customer. Furthermore, a Scrum Master supports the development team regarding to the process and boundary conditions (Schwaber and Sutherland, 2017).

As Scrum was developed primarily for software development, there is a need to adapt the approach in mechatronic development projects. Several frameworks can be found in literature. Klein (2016) adapted the elements of scrum to his agile engineering framework. Elements of Scrum are combined and implemented to a project depending on the different degrees of agility (Klein, 2016). The approach of Sommer et al. (2013) combines Scrum with a stage gate process. Reittinger (2017) also developed the agile hybrid model for hardware development based on scrum. The framework includes iterations, different roles, and artefacts as well. Differences are a product owner team, which can work in different iteration lengths and every 12 weeks is a release (Reittinger, 2017). Hostettler et al. (2017) developed the TAF agile Framework. The framework combines lean startup, design thinking, scrum, and elements of mechatronic development methods. The framework is used for so-called makeathons. To integrate risk management to the agile product development initial approaches exist. One approach or philosophy is to prioritise user stories regarding to their risks. After that, the user story with the highest risk will be developed first (Tomanek and Juricek, 2015). Another approach is to integrate the entire risk management process to the agile framework and link every step of risk management with an element of an agile framework (Nyfjord and Kajko-Mattsson, 2008) developed a tool that also combines both frameworks. Furthermore, the tool identifies indicators, which identify risk and challenges of tasks, resources or competences (Odzaly et al., 2014). Andrat and Jaswal (2015) developed a risk matrix that identifies dependencies between different risks and effects between them. Goevert et al. (2019) describe a risk matrix that identifies user story risks depending on the risk of non-fulfilment and possible damages.

The agile frameworks for mechatronic product development show various approaches to integrate agile elements into the process. All of them use parts of scrum. In the approach of this paper and the case study, the approach of Goevert and Lindemann (2018) and Goevert (2020) is applied. The approach combines agile elements and frameworks depending on the results of the project situation analysis. A risk matrix, as Andrat and Jaswal (2015) described, is an interesting approach to combine agility and risk management. However, not only the risk, which results from interdependencies, is interesting in mechatronic projects. Aside from that, external risks are interesting in agile mechatronic projects, as the team cannot influence them. This makes planning in individual iterations very difficult.

\section{Research question and methodology}

As described in the first section the research goal is to adapt agile methods to the mechatronic product development and to integrate elements of risk management. To achieve this goal, the design research methodology (DRM) of Blessing and Chakrabarti (2009) is applied. At the beginning, an initial literature research was executed, the research goal was defined, and a research question derived from the research.

The research question is: How can agile elements be integrated into the mechatronic product development process and how can risk management support the process without reducing agility?

After that, a detailed literature review was conducted. The literature review focuses on agile frameworks of mechatronic product development and on the integration of risk management and agile elements. This is part of the descriptive study 1 . The next step was the prescriptive study where solution elements are developed. Here, the focus was set on the integration of the risk management into agile projects. The main part of this paper focuses on the descriptive study 2 , which entails the evaluation of the agile element implementation to the mechatronic product development and the combination of agile methods and risk management (Blessing and Chakrabarti, 2009). 


\section{Results}

\subsection{Case study partner}

The industrial partner of this case study is "SEBA Hydrometrie GmbH \& Co. KG" a Bavarian SME, developing and producing mechatronic devices in the field of hydrology, meteorology and sewage. The case study partner never used agile approaches in their projects before. In addition, the company had no defined product development process. To investigate the boundary conditions for this case study, the initial situation regarding the implementation of agility was assessed, based on interviews with the head of development, the project leader, and the responsible sales manager. The structured interviews consisted of 37 closed questions. The questions focused on the topics:

- Organization,

- Product and Process management,

- Product,

- Project,

- Team,

- Change management, and

- Scaling.

Beneficial for the implementation of agile development methods were especially the following - the team is located at one side, a direct contact with the user of the product is possible, and it is possible to build and test prototypes within the company. On the other hand, the biggest challenges were identified in the field of "organisation". The lack of a suitable tool for agile development, but also the lack of knowledge of the team members regarding agile methods led to this assessment. Further, team members were assigned to several projects hindering the required freedom for a fully self-organized team. In addition, some stakeholders were sceptical about agile methods, which might be an impediment to the implementation.

\subsection{Adaption of agile approaches}

In this case study the selection, adaption, and implementation of agile methods were planned using the agile methods toolbox of Goevert and Lindemann (2018), the findings of Goevert et al. (2019) on the integration of mechatronic product development methods in agile projects, and the final adaption procedure of Goevert (2020). Overall, it was decided to take a Scrum based approach. Thus, responsibilities were defined - The project leader was assigned as scrum master, and the sales manager as product owner. In a first step, the scrum master, product owner, and the head of development, assigned a set of project-specific characteristics or boundary conditions to the roles scrum master, product owner, Technical University of Munich (TUM), and the development team. This task aimed at identifying required criteria for agile development that are not yet entailed by the involved people. The result is shown in Figure 1. Five elements were identified to be completely or partially missing among the project team. Consequently, the following solutions to overcome these shortcomings were derived by Goevert (2020):

- Limited affinity for methods: Training workshop at the beginning of the project and further support during the sprints by the authors of this paper.

- Availability of team members is unknown in the beginning: Each team member roughly estimates its capacity for the upcoming sprints. User Stories will be assigned with respect to this estimation. Optional User Stories can be defined to avoid lack of workload

- Not every team member can take on every task: User Stories will be assigned to single people with respect to their capacity, their competences, and the estimated effort of the User Story.

- Complicated production of prototypes (hardware, design): The focus is set on functional prototypes, which do not require to be produced. 


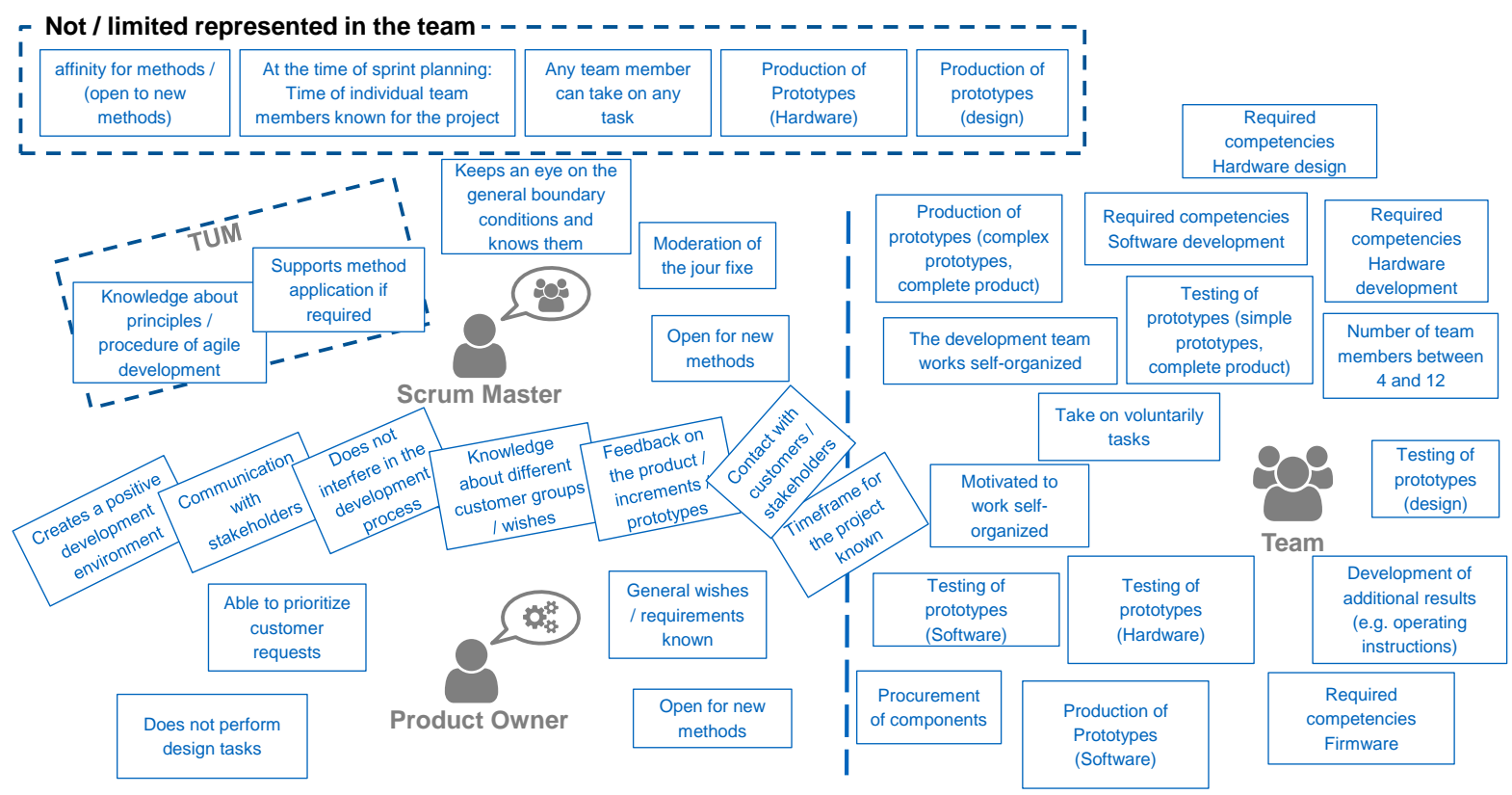

Figure 1. Selected agile methods (Goevert, 2020)

The results were considered in the derived development approach. Using the core elements of scrum, it was decided to execute planning meetings followed by sprints, which were closed by a product review and a process retrospective. In each planning meeting, the attendants estimated the effort of the user stories to be executed. The duration of the sprints was not fixed in the beginning. Instead, it was defined in each planning meeting with respect to the available resources, holidays, or external influence factors such as the availability of suppliers. However, the sprints were never shorter than four weeks or longer than six weeks. The team members were assigned to the user stories with respect to their workload. User Stories could only be considered in a sprint if the required employees had enough capacity remaining. Otherwise, they were classified as optional. As the production of prototypes is complicated at the company, it was decided to use mostly non-physical prototypes. Together with the company, it was decided to use functional prototypes, CAD-drawings, software mock-ups, graphical user interfaces, and digital 3D-models. This selection was made with respect to the preference and competences of the product owner, as he needs to understand and consequently assess the developed increment in the product review.

\subsection{Case study project}

This case study, parts of which are described in in Goevert (2020), dealt with the development of a mechatronic component. Focus of the project was a new product for hydrological measurements that was based on existing and new components. Software, hardware as well as system integration had to be developed. Challenging was the implementation of a new transmission technology, which had not been used in the company so far. The core team of the project consisted of four to six people. In total up to ten people were involved in the project incorporating the disciplines research and development, software development, firmware development, hardware development, testing, manufacturing, and sales. Prior to the case study, a development period of eight months was planned. Further, the overall goal as well as some general requirements and tasks were defined. The project without preliminary planning was accompanied from mid-March 2019 until the beginning of August 2019 by the authors of this paper. During this period, four sprints were completed. To complete the project the company conducted further sprints on their own, which are not part of the presented paper.

In the first sprint planning meeting the overall vision of the project was presented to the development team. Based on the vision, user stories were defined, prioritized, and their interdependencies were documented. After the first sprint, a preliminary graphical user interface, functional prototypes, as well as their testing results were presented to the product owner. In the retrospective, a two-factor method was used, assessing the development process (cf. Figure 5, "Sailboat"). Especially the lack of 
knowledge regarding the agile methodology and the insufficient level of detail of the User Stories was emphasized. In the planning for the second sprint, the results of the first sprint could be used and only had to be slightly adapted, respectively supplemented by further user stories.

In the product review of sprint two, the functional prototype of sprint one was presented with additional functions included. In the retrospective, a four-factor method was used (cf. Figure 5, "Portfolio"). Before this sprint, the development team had no regular meeting during the sprint. Thus, it was decided to implement a weekly meeting. Further, it was recognized, that some User Stories were to extensive to be estimated properly. Consequently, sub User Stories were defined. Lastly, as it was already expected from the company's initial situation (cf. section 4.1), the lack of an appropriate digital tool is problematic. In course of this project it was not possible to implement a suitable tool. However, the company is working on implementing one in the near future. The sprint planning was executed the same way as in the previous sprints.

The same procedure was taken for sprints three and four. As for sprint one and two, extended functional prototypes were presented to the product owner. The granularity of the retrospective method however was increased by considering five factors (cf. Figure 5, "Starfish"). Aside from the missing digital project management tool, mostly minor problems considering the daily teamwork were identified. In the sprint planning meeting for sprint five an adapted risk management method was applied which is described in the following section 4.4. After the fourth sprint, two more sprints were executed, which were not accompanied by the authors of this paper. In these last two sprints the methodology was applied in the same manner by the scrum master.

\subsection{Risk management in agile projects}

In order to ensure the project success after the completion of sprint 6 , measures of risk management were introduced at the planning meeting of sprint 5. This measure had already been applied in previous projects of the research partner with positive effects on the timely delivery outcomes (cf. Goevert, 2020). The method is carried out as follows: In the planning meeting of the sprint before the last sprint, a so called User Story Risk Map is created that evaluates the risk of each user story that is not yet fulfilled at this point of time (inspired by Andrat and Jaswal, 2015). As in many contributions on risk management, risk is regarded as the combination of the damage caused by not fulfilling the user story and the probability of a user story not to be fulfilled (Strohmeier, 2007).

Every open user story is placed within the user story risk map with special regard to external factors like the probability of a part from a supplier not being delivered in time or a person getting ill so that they can no longer perform the tasks they have been assigned. As a result, all open user stories are assigned to one of the three categories Low Risk Zone, Observation Zone, Problem Zone (cf. Figure 2).

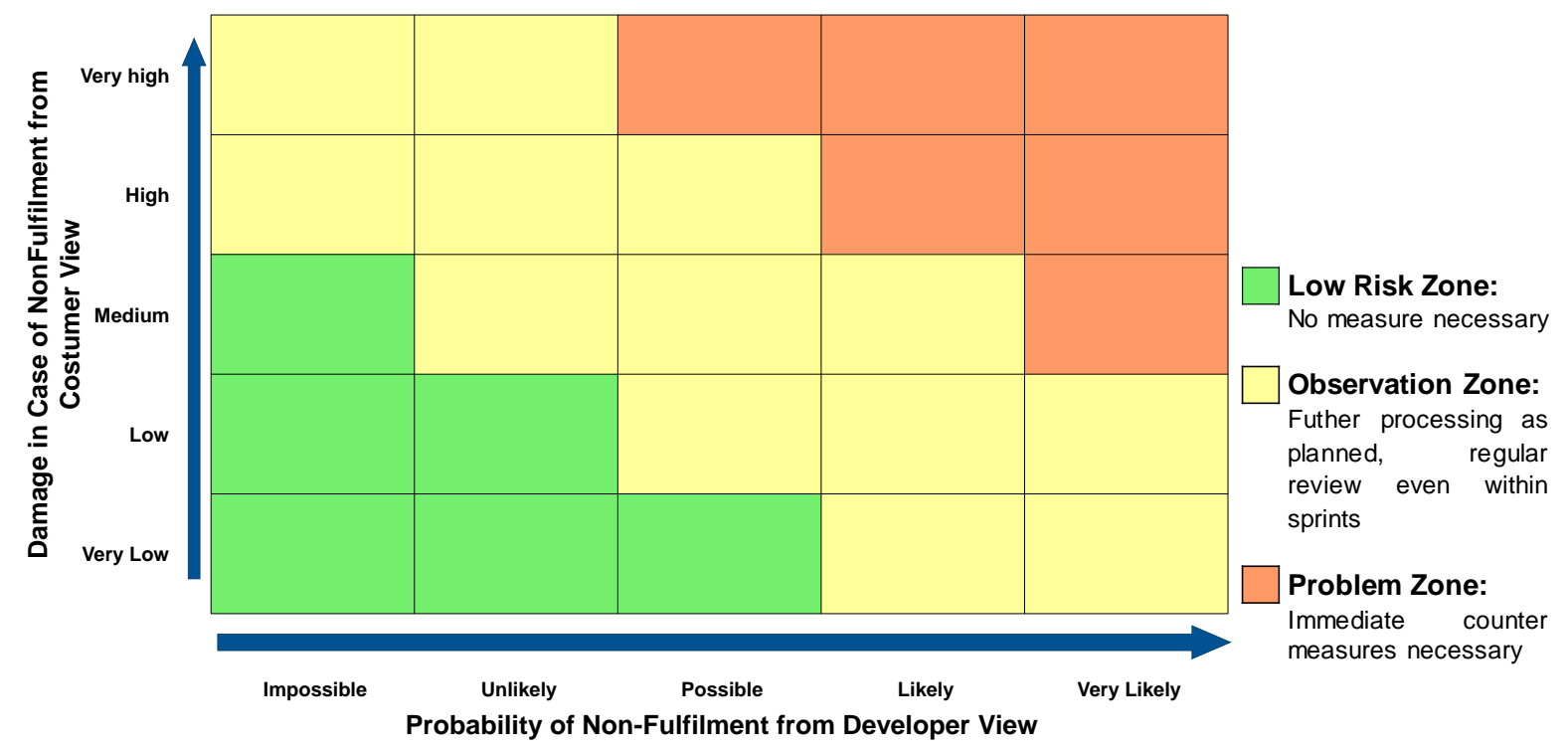

Figure 2. User story risk map 
Low Risk Zone: As there is no high damage to be feared and the probability of not being able to complete a user story is not very high, no further measures have to be taken. A standard sprint planning according to the given prioritization can be performed.

Observation Zone: In contrast to the standard Scrum procedure of evaluating outcomes at the end of a sprint, user stories in the observation zone might need more management attention in order not to pose a threat to the overall project goals. Therefore, additional short reviews within the sprint just regarding these specific user stories shall be performed. Depending on the chosen sprint length, there might be two or even more short reviews in the duration of one sprint.

Problem Zone: As they set the overall project at risk, user stories in the problem zone have to be dealt with immediately. Counter measures like early warnings towards the costumer, a reduction of the expected outcome, a weakening of some acceptance criteria, an increase of resources, or the prioritization in relation to other projects have to be chosen. As in the observation zone, some shorter review cycles should be installed, leading to some short reviews within the sprint to check the effectiveness of counter measures and whether other immediate measures are necessary.

After all counter measures have been planned, the user stories are re-evaluated and their position is altered with regard to the expected changes in probability of non-fulfilment and possible damage. Ideally, this can move all user stories from the problem zone at least to the observation zone. In most cases it will be easier to move user stories from right to left, i.e. reduce the probability of nonfulfilment e.g. by allocating additional resources, than from top to the bottom. Attention has to be paid as some counter measures like the increase of resources may have some effects on other user stories, as their relative priority will decrease. After all user stories have been placed in their final position with regard to the selected counter measures, the sprint planning can be performed. It should be checked whether the positioning of the user stories also leads to an alteration in their priorities. If so, there should be an increase in priority from bottom left to the upper right corner. It is important that as a result of the planning according to the user story risk map, resources are focused on the problem zone without leaving behind some low-hanging fruits in the bottom left corner.

Figure 3 (before the planning of counter measures) and 4 (after the planning of counter measures) show the application of the user story risk map in a workshop at the industry partner.

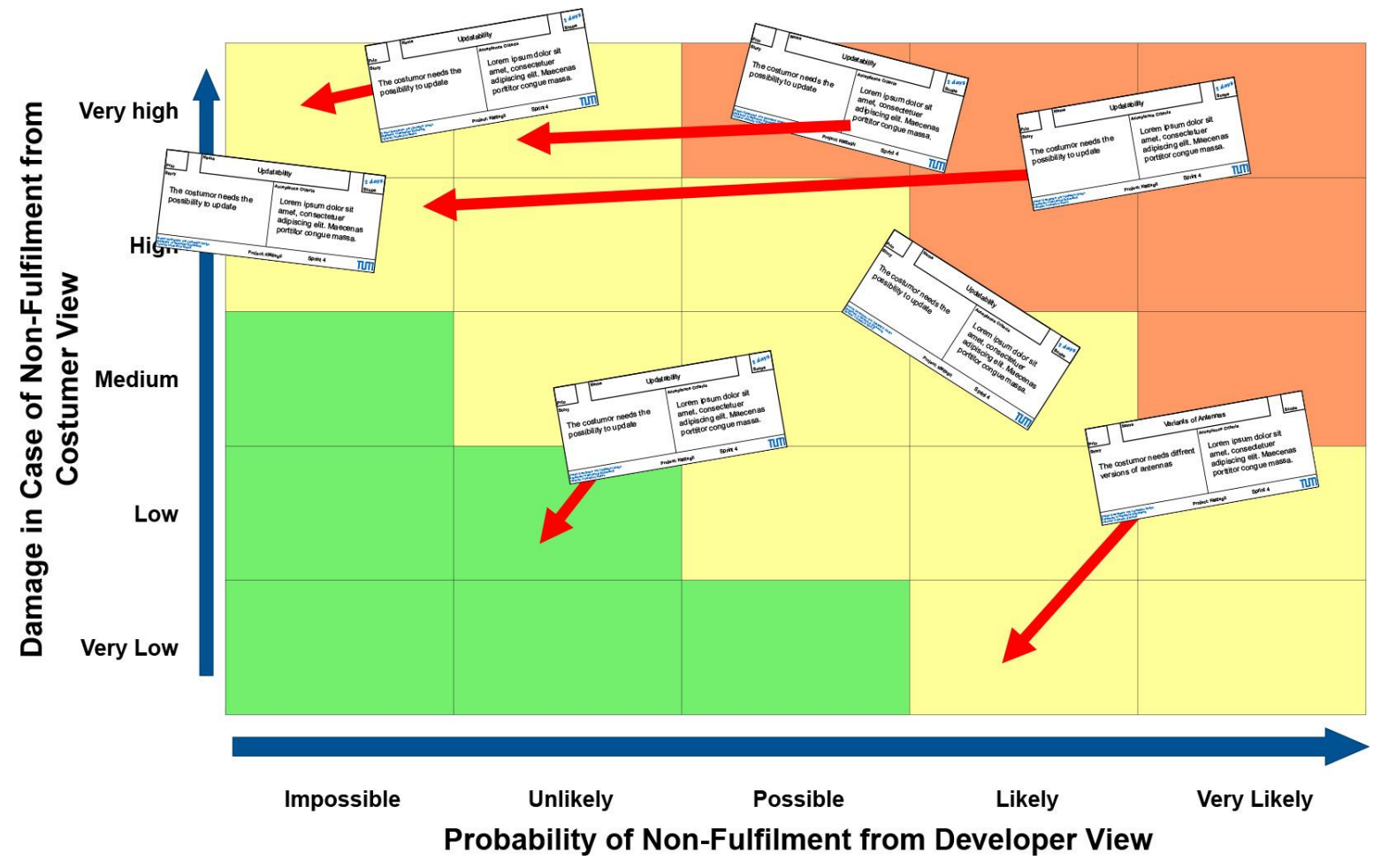

Figure 3. User story risk map before measures to lower the risk were planned 
Counter measures were installed that move all user stories at least into the observation zone. The most effective measure was to pause the activities of some team members in other projects so that they could only focus on their tasks in the project investigated here.

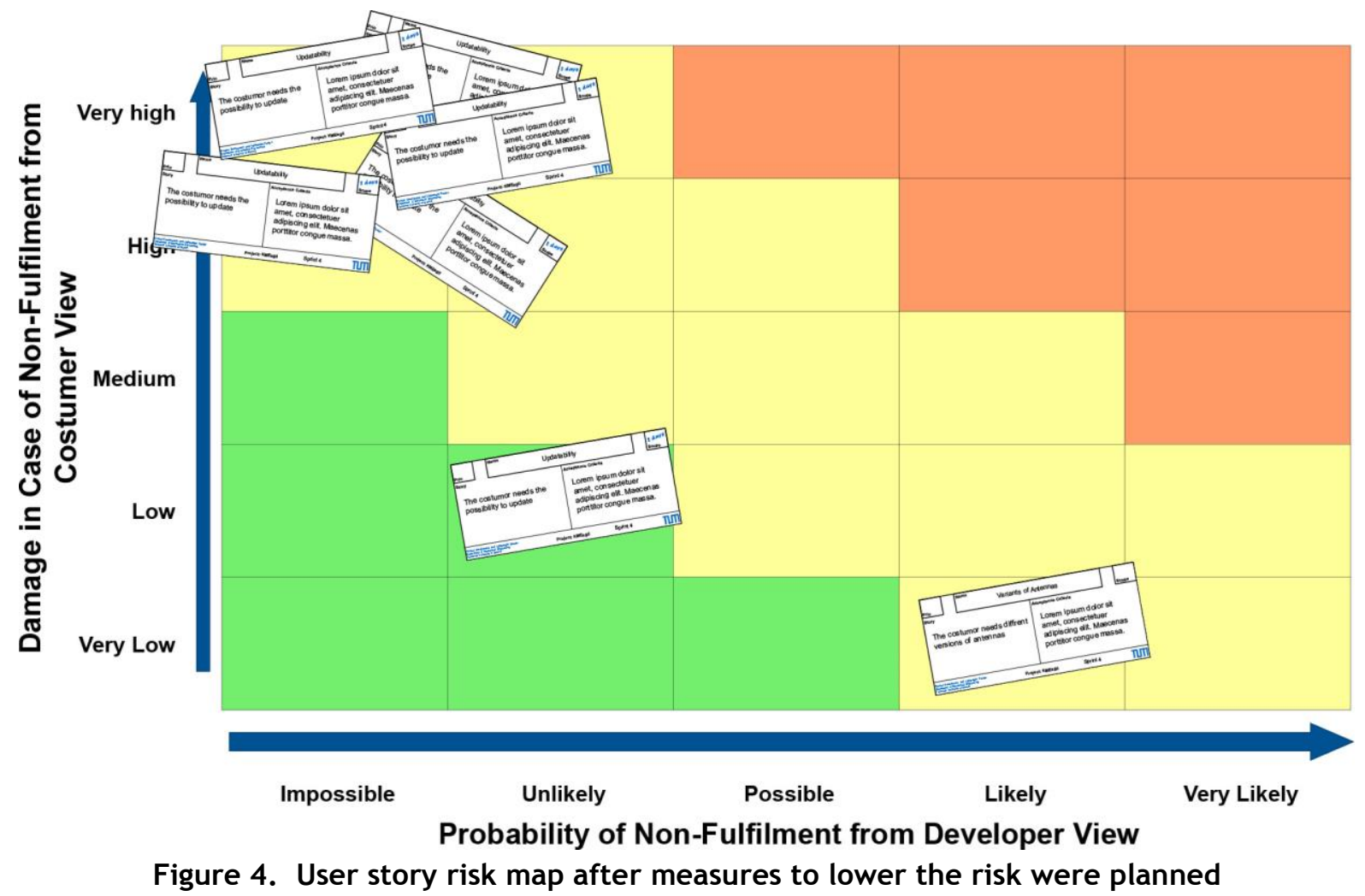

\section{Evaluation}

In regular feedback sessions at the end of each of the four workshops with the industry partners, elements for continuous process improvement were gathered. The workshops had between four and six participants. As already mentioned in section 4.3, different methods were used to stimulate valuable feedback and structure the derived improvement measures (partly taken form Andresen, 2017). The complexity of the methods was increased with every workshop to ensure the involvement of all participants and to not overwhelm them with to sophisticated methods in the beginning (cf. Figure 5).
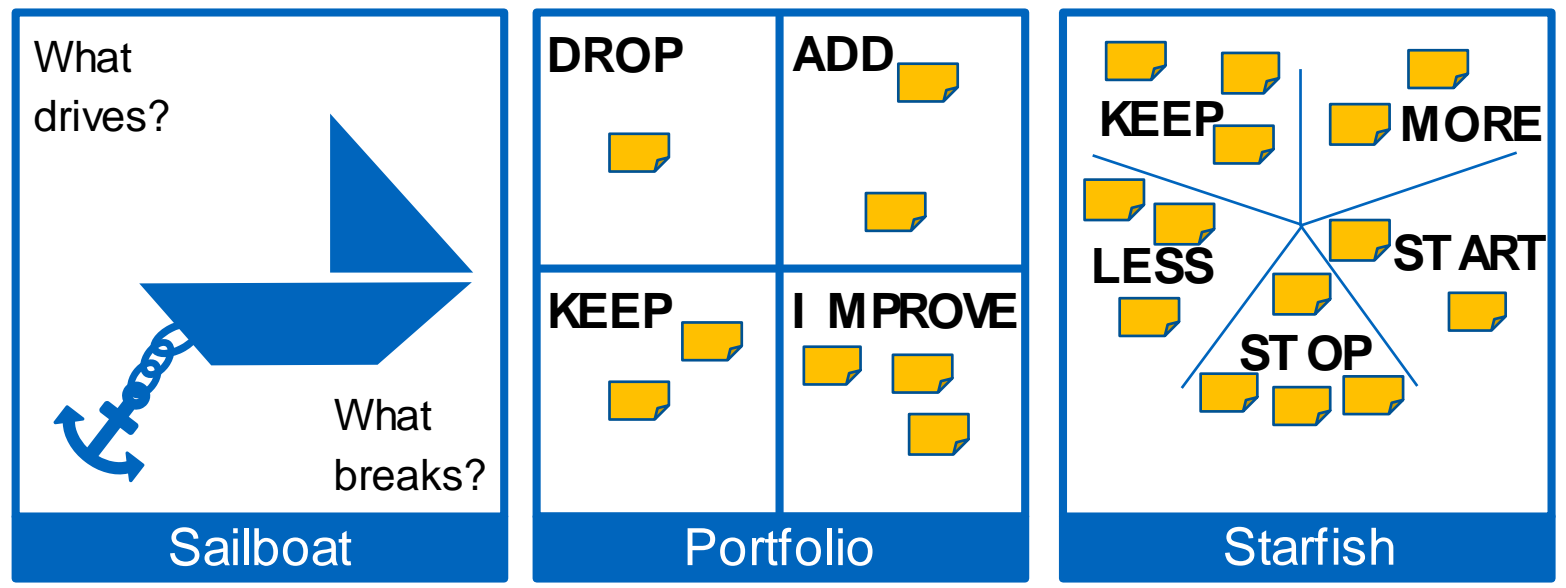

Figure 5. Feedback methods used in the workshops with the industry partner: Sailboat (Workshop 1), Feedback Portfolio (Workshop 2), and Starfish (Workshops 3 and 4) 
Six participants took part in the final workshop, the main part of this section comes from. Figure 5 shows the central elements of the evaluation in a starfish diagram. The yellow cards depict all feedback elements mentioned by the participants. Pink cards represent the improvement measures that were derived from in the discussions triggered by the feedback. Finally, on blue cards there are measures that had already been implemented as the result of previous feedback session.

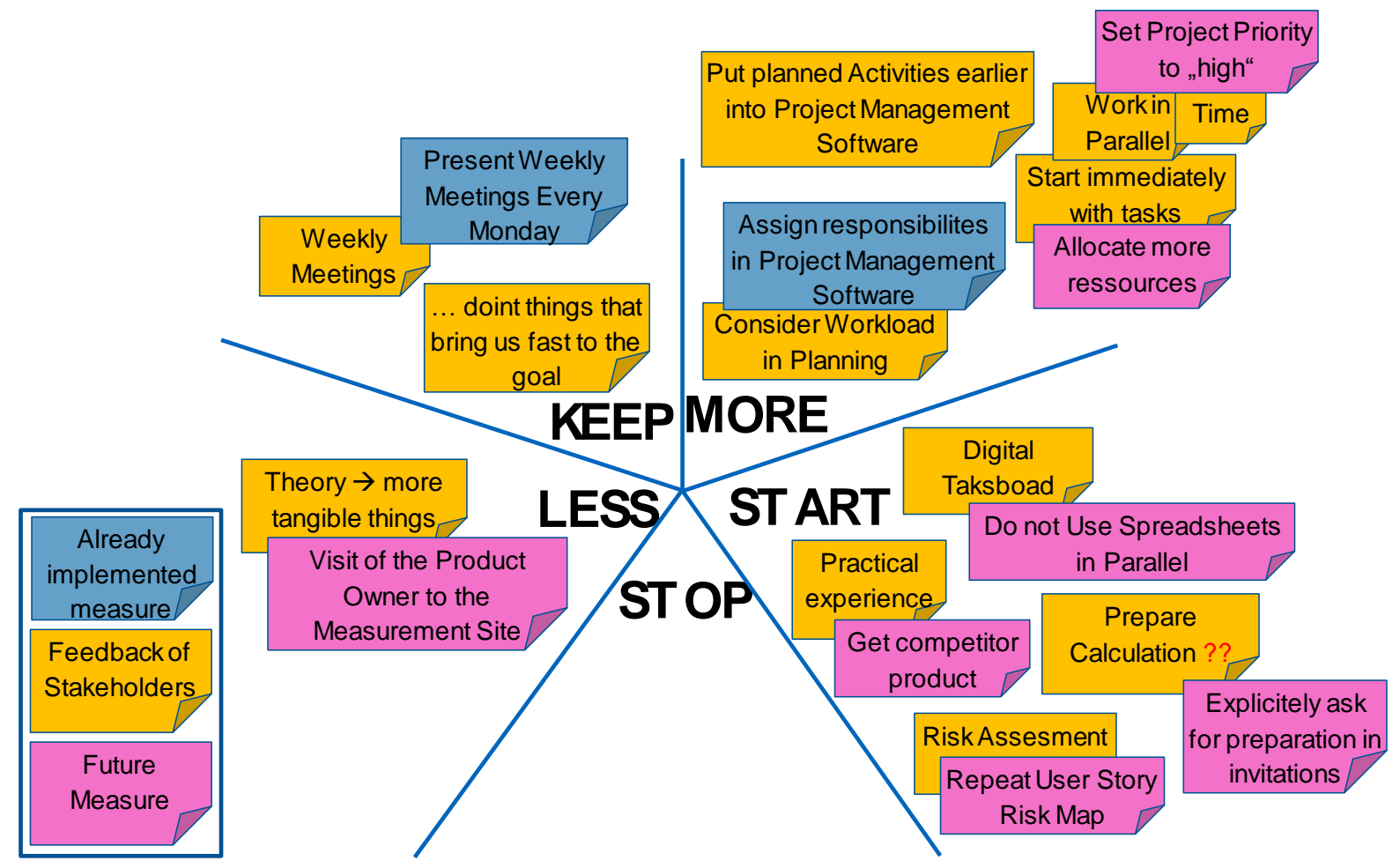

Figure 6. Elements of the final feedback session

Many elements of the final feedback session prove the success of the implementation of agile methods. Techniques like weekly meetings are kept while theoretical work is decreased so that the product owner is integrated earlier. The assessment of the user story risk in the user story risk matrix leads to more resources being allocated to the project. The method itself was rated as very helpful and will be repeated within the final sprints as well as at the end of sprints.

\section{Conclusion and outlook}

\subsection{Discussion}

The main result of this presented case study is the risk management method for agile projects. To date, literature is still lacking suitable risk management methods for agile mechatronic product development. The approach, which was inspired by Andrat and Jaswal (2015), was evaluated positively for this case study. Especially the possibility to use this method to prioritize User Stories based on their risk, provided an additional value for the case study partner - not only possible sources of risks were uncovered, but also the prioritization of User Stories was derived more objectively. This observation is in line with literature, e.g. the publication of Tomanek and Juricek (2015) The analysis of the current situation and the method for adapting the agile development approach also proved their applicability in this case study. Impediments such as a missing digital project management tool, or the limited affinity for agile methods, were identified in early phases, and thus it was possible to adapt to these shortcomings. As the industrial partner did not have a specified development process yet, the participants highlighted especially the benefits from a more structured, systematic procedure introduced by the agile development approach. Overall, the company was able to successfully complete the development project. 


\subsection{Outlook}

The presented User Story risk map was applied only in the last sprints of the case study. However, the authors would suggest using this method from the first sprint on. To higher the benefits of this method for sprint planning, a more formalized way of deriving priorities from the risk assessment should be developed. Further, as especially financial risks are high in agile projects, it might be beneficial to combine this risk assessment with budgeting approaches such as the structured agile budgeting process of Vierlboeck et al. (2019).

\section{Acknowledgements}

The authors thank Christian Satzger and Arthur Bauer, as well as the complete development team of SEBA, for the very fruitful collaboration.

\section{References}

Albers, A. et al. (2018), Eine Systematik zur situationsadäquaten Mechatroniksystementwicklung durch ASD Agile Systems Design. https://doi.org/10.5445/IR/1000091847

Andrat, H. and Jaswal, S. (2015), An alternative approach for risk assessment in Scrum. In CoCoNet (Ed.): 2015 International Conference on Computing and Network Communications (CoCoNet). 16-19 Dec. 2015. https://doi.org/10.1109/CoCoNet.2015.7411239

Andresen, J. (2017), "Retrospektiven in agilen Projekten: Ablauf, Regeln und Methodenbausteine", Carl Hanser Verlag GmbH Co KG.

Beck, K. et al. (2001), "Manifesto for Agile Software Development", Agile Alliance. Available online at https://www.agilealliance.org/agile101/the-agile-manifesto/, checked on 11/25/2019.

Blessing, L.T.M. and Chakrabarti, A. (2009), DRM, a Design Research Methodology. London: Springer London. https://doi.org/10.1007/978-1-84882-587-1

Boehmer, A.I. (2018), "When digital meets physical - Agile innovation of mechatronic systems", Dissertation. Technical University of Munich, München. Available online at https://mediatum.ub.tum.de/doc/1430507/ 1430507.pdf, checked on 11/25/2019.

Goevert, K. (2020), "Implementierung von agiler Entwicklung in den mechatronischen Produktentstehungsprozess", submitted in October 2019. Dissertation. Technical University of Munich, Munich, Germany.

Goevert, K., Brombeiss, M. and Lindemann, U. (2019), "Integration of Mechatronic Product Development Methods in an Agile Development Area", In A. Chakrabarti (Ed.): Research into design for a connected world. Proceedings of ICoRD 2019. Volume 2 / editor, Amaresh Chakrabarti, vol. 135. Singapore: Springer (Smart Innovation, Systems and Technologies, volume 135), pp. 119-131. https://doi.org/10.1007/978-98113-5977-4_10

Goevert, K. Lindemann, U. (2018), "Further Development of an Agile Technique Toolbox for Mechatronic Product Development", In: Proceedings of the DESIGN 2018 15th International Design Conference. 15th International Design Conference, May, 21-24, 2018: Faculty of Mechanical Engineering and Naval Architecture, University of Zagreb, Croatia; The Design Society, Glasgow, UK (Design Conference Proceedings), pp. 2015-2026. https://doi.org/10.21278/idc.2018.0204

Goevert, K., et al (2019, July), "Agile Development of a Microtiter Plate in an Interdisciplinary Project Team", In Proceedings of the Design Society: International Conference on Engineering Design (Vol. 1, No. 1, pp. 2139-2148). Cambridge University Press. https://doi.org/10.1017/dsi.2019.220

Hofert, S. (2016), Agiler führen. Wiesbaden: Springer Fachmedien Wiesbaden. https://doi.org/10.1007/978-3$658-12757-2$

Hostettler, R. et al. (2017): TAF agile framework reducing uncertainty within minimum time and resources. In: 2017 International Conference on Engineering, Technology and Innovation (ICE/ITMC). 2017 International Conference on Engineering, Technology and Innovation (ICE/ITMC). Funchal, June 27-29, 2017. [S.1.]: IEEE, pp. 767-775. https://doi.org/10.1109/ICE.2017.8279962

Klein, T. (2016), "Agiles Engineering im Maschinen- und Anlagenbau”, München: Herbert Utz Verlag (Forschungsberichte IWB, Band 323).

Nyfjord, J. and Kajko-Mattsson, M. (2008), "Outlining a Model Integrating Risk Management and Agile Software Development", In: 34th EUROMICRO Conference Software Engineering and Advanced Applications, 2008. SEAA '08; 3 - 5 Sept. 2008, Parma, Italy. 2008 34th Euromicro Conference Software Engineering and Advanced Applications (SEAA). Parma, Italy, 9/3/2008 - 9/5/2008. Annual IEEE Computer Conference; EUROMICRO Conference on Software Engineering and Advanced Applications; SEAA. Piscataway, NJ: IEEE, pp. 47-483. https://doi.org/10.1109/SEAA.2008.77 
Odzaly, E. Des G. and Stewart, D. (2014), "Lightweight Risk Management in Agile Projects", In M. Reformat (Ed.): 26th International Conference on Software Engineering and Knowledge Engineering. 26th Software Engineering Knowledge Engineering Conference. Vancouver, Canada. Knowledge Systems Institute Graduate School, pp. 576-581. https://doi.org/10.13140/2.1.4681.0882

Project Management Institute (2017), A guide to the project management body of knowledge. PMBOK Guide. Sixth edition. Newtown Square, Pennsylvania, USA: Project Management Institute (PMI global standard).

Reittinger, A. (2017), "Hybrid Agile - best of two worlds", In A. Schröder (Ed.): Agile Produktentwicklung. Schneller zur Innovation - erfolgreicher am Markt. München: Carl Hanser Verlag GmbH \& Co. KG, pp. 218-234. https://doi.org/10.3139/9783446452459.010

Schmidt, T.S. Weiss, S. and Paetzold, K. (2018): Agile Development of Physical Products. An Empirical Study about Motivations, Potentials and Applicability. Neubiberg, Germany: Universität der Bundeswehr München.

Schwaber, K. and Sutherland, J. (2017), "The Scrum Guide", The Definitive Guide to Scrum: The Rules of the Game. Scrum.org. Available online at https://www.scrumguides.org/docs/scrumguide/v2017/2017-ScrumGuide-US.pdf\#zoom=100, checked on 11/13/2019.

Sommer, A.F. et al. (2013), "Scrum integration in stage-gate models for collaborative product development - A case study of three industrial manufacturers", In: IEEM 2013. 2013 IEEE International Conference on Industrial Engineering and Engineering Management: 10-13 December 2013, Bangkok, Thailand. 2013 IEEE International Conference on Industrial Engineering and Engineering Management (IEEM). Bangkok, Thailand, 12/10/2013 - 12/13/2013. Piscataway, NJ: IEEE, pp. 1278-1282. https://doi.org/10.1109/IEEM. 2013.6962616

Strohmeier, G. (2007): Ganzheitliches Risikomanagement in Industriebetrieben: Grundlagen, Gestaltungsmodell und praktische Anwendung: Springer-Verlag.

Tomanek, M. and Juricek, J. (2015), "Project Risk Management Model Based on PRINCE2 and Scrum Frameworks", In IJSEA, Vol. 6 No. 1, pp. 81-88. https://doi.org/10.5121/ijsea.2015.6107.

Vierlboeck, M. et al. (2019), "Budgeting for Agile Product Development", In Proc. Int. Conf. Eng. Des., Vol. 1 No. 1, pp. 2169-2178. https://doi.org/10.1017/dsi.2019.223. 